\title{
Emotional Exhaustion and Its Correlation with Job Performance and Job Satisfaction in the Kingdom of Saudi Arabia
}

\author{
Dr. Mohammed Owais Qureshi (Corresponding Author)
}

Faculty, Department of Human Resource Management, College of Business, King AbdulAziz University, Rabigh, Kingdom of Saudi Arabia

Email ID: moghashmi@gmail.com

\section{Dr. Syed Rumaiya Sajjad}

Head \& Assistant Professor, Department of Health andHospital Management, College of Business, King AbdulAziz University, Rabigh, Kingdom of Saudi Arabia

Email ID: tehzeeb001@gmail.com

\section{Doi:10.5901/mjss.2015.v6n3s1p51}

\section{Abstract}

The aim of this study is to find the impact of emotional exhaustion amongst employees working in the Kingdom of Saudi Arabia. Furthermore, the study also aims to access the relationship between emotional exhaustion \& job performance and emotional exhaustion \& job satisfaction. To achieve these aims, the four factors of emotional exhaustion are identified and their relationship with job performance and job satisfaction examined. In order to explicate these aims the researchers first discuss the concept of emotional exhaustion and identify four factors of emotional exhaustion. And then the relationship between job performance and job satisfaction is reviewed, with the four factors of emotional exhaustion. Considering the findings, the researchers conclude that the impact of emotional exhaustion is low in employees working in the Kingdom of Saudi Arabia and also, that emotional exhaustion is inversely related to both job performance and job satisfaction. The current research points out, that the relationship of job performance and job satisfaction with emotional exhaustion is strong in the Kingdom of Saudi Arabia. The research paper is based on quantitative analysis and it explores how lesser emotional exhaustion can improve the performance and job satisfaction of an employee working in the Kingdom of Saudi Arabia. This study also provided concrete insights about employees' views on emotional exhaustion, job performance and job satisfaction.

Keywords: Emotional Exhaustion; Job Performance; Job Satisfaction; Human Resource; Saudi Arabia;

\section{Introduction}

The Kingdom of Saudi Arabia is one of the most important international markets of the developing world and the human resources in the kingdom are playing a very crucial role in the economic development of the country. Thus, a developing and economically ever growing Saudi Arabia provides an ideal background for the research on emotional exhaustion, and its correlation with job performance \& job satisfaction of employees.

The traditional ways of competitive advantage have to be supplemented with organizational capability i.e. the firm's ability to manage people (Ulrich and Lake 1990). Emotional exhaustion is a chronic state of physical and emotional depletion that results from excessive job and/or personal demands and continuous stress. (Wright, June 1998). To manage emotional exhaustion, evaluation of employees' performance is a critical provision amid firms. It provides vital information regarding the productivity of an employee and allocation of benefits that characterize such provisions. Additionally, periodic appraisals act as the driving force for exemplary performances amid employees (Capko, 2003). Conducting fair performance assessments is crucial to avoid unwarranted prejudice and promote the objectivity, productivity, and responsibility of employees (Campion et al. 2011). Research conducted by Judge et al (1998), Judge and Bono (2001) indicated that core self-evaluation plays a significant role as a vital personality attribute that relates with the employee job satisfaction.

This research paper thus, examines the effect of emotional exhaustion amongst the personnel working in the Kingdom of Saudi Arabia. It draws attention to the influence of emotional exhaustion on job performance and job satisfaction of an employee, thus, accessing the relationship between them.

The paper offers information on the research background, the sample and the methods used in the study. Lastly, 
the scholars present the empirical results and debate on the importance of the results.

\section{Literature Review}

This section looks at the concept of emotional exhaustion, correlation between emotional exhaustion and job performance, emotional exhaustion and job satisfaction.

\subsection{Emotional Exhaustion}

Emotional exhaustion is a chronic state of physical and emotional depletion that results from excessive job and/or personal demands and continuous stress. (Wright, June 1998). Burnout, a term used to describe a particular type of stress reaction or strain, is defined as a syndrome of emotional exhaustion and cynicism towards one's work in response to chronic organizational stressors (Maslach \& Jackson, 1981, 1982b). Emotional exhaustion is one of the more extreme varieties of work related strains. It manifest in employees as a general loss of feeling and concern, trust, interest and spirit. (Maslach, 1982)

There are a number of factors that affect the incidence of emotional exhaustion. The research has tended to indicate that situational rather than person (or individual-difference) factors are the key predictors (Moore, 2000). Emotional exhaustion has properties similar to ordinary states of fatigue, but is closer to chronic fatigue because of its pervasive and enduring qualities (Griffith, Kerr, Mayo, \& Topal, 1950). Research has suggested that chronic fatigue is a concomitant of physical ill health (Bartely \& Chute, 1947). Thus, poor physical and mental health of an employee is an indicator of emotional exhaustion, which serves as a unique quality of working life indicator. Emotional exhaustion thus has the potential to estimate the cumulative effects of work stresses. Built on the conceptions discussed above we postulated that although poor health has a consequence on the emotional exhaustion of an employee, but employee working in the Kingdom of Saudi Arabia, do not have compromised physical and mental health because of the working conditions. (Hypothesis 1)

The existence of a high workload is perhaps the most consistent predictor of emotional exhaustion (Lee and Ashforth, 1996). Job-related burnout is one of the most likely outcomes of the performance of emotional labour. She believed that staff who were employed in jobs with sustained customer contact and few opportunities to vary the nature of their displayed feelings risked high levels of stress Hochschild $(1979,1983)$. Morris and Feldman (1997) also considered that frequent interpersonal interactions with clients of an emotionally intense nature could be expected to lead to emotional exhaustion. Strong social support from supervisors has been identified in other studies as an important resource which can reduce emotional strain (Lee and Ashforth, 1996)

These principally relate to the nature of the work demands placed upon individuals. Amongst the most important of these factors are workload, role overload, work pressure and role conflict (Cordes and Dougherty, 1993). High workload, in particular, has consistently been linked to emotional exhaustion in a range of studies (Jackson et al., 1986; Maslach and Pines, 1977). Furthermore, where individuals feel that they lack the training and skills to deal satisfactorily with the requirements of their job (role overload) they are more likely to experience emotional exhaustion (Maslach and Pines, 1977). Workload Extent to which pace of work is regarded as excessive (Caplan et al.,1975)

Built on the conceptions discussed above we postulated that although work overload has a consequence on the emotional exhaustion of an employee, but personnel working in the Kingdom of Saudi Arabia, do not have work-overload that could lead to emotional exhaustion. (Hypothesis 2)

Interpersonal aspects of work, including supportive leader behavior and group cohesiveness, play an important part in decreasing the incidence of emotional exhaustion. (Cherniss, 1980; Freudenberget, 1974; Maslach, 1976; Mattingly, 1977) discovered that frequent staff meetings in which employees could share experiences and provide support each other were related to lower rates of emotional exhaustion. Based on this context we would hypothesize that in the Kingdom of Saudi Arabia employees feel that they receive sustenance from their team members and from their team leaders and thus the employees working in the Kingdom of Saudi Arabia do not have strained relationship with their colleagues and supervisors. (Hypothesis 3 )

The worker would rather desire working conditions that will result in greater physical comfort and convenience. The absence of such working conditions, amongst other things, can impact poorly on the worker's mental and physical wellbeing (Greenberg and Baron, 1993). Further, Arnold and Boshoff (2001) shows that factors such as temperature, lighting, ventilation, hygiene, noise, working hours, and resources are all part of working conditions. Employees may feel that poor working conditions will only provoke negative performance, since their jobs are mentally and physically demanding. Based on this context we would hypothesize otherwise, that in the Kingdom of Saudi Arabia employees do not have a 
feeling of negativity at work and thus they experience less emotional exhaustion. (Hypothesis 4)

\subsection{Emotional Exhaustion and Job Performance}

Emotional exhaustion can have a deleterious affect on the job performance of an employee and in turn on the productivity of the organization. Russell Cropanzano and his colleagues, in their two field work, show that fatigued employees show poorer organizational commitment, lesser job performance, less organizational citizenship behaviors (OCB) directed toward the organization (OCBO) and their supervisors (OCBS), and higher turnover intents. They recommend that emotional exhaustion can been understood as a worth that qualifies the value of any profits received through employment, and so that an organization, which overburdens its employees to the point of emotional exhaustion, may be seen as imbalanced. Similarly, longitudinal studies found that fatigued employees show not only poorer job performance, but also more nonappearances, and greater possibility of seeking employment somewhere else (Emotional exhaustion, the freedictionary). It describes a feeling of being emotionally overextended and exhausted by one's work. It is manifested by both physical fatigue and a sense of feeling psychologically and emotionally "drained". Zohar D. (1997). "Predicting burnout with a hassle-based measure of role demands". Journal of Organizational Behavior 18 (2): 101-115. Wharton (1993) found that a lack of opportunities for self-monitoring increased the likelihood of emotional exhaustion. Now, when the burnout is more, compensation is not at par with the market standards, these factors will have a negative impact on the job performance of the employee.

Lo, Cravens, Grant, and Moncrief (2001) in their study on salespersons in Australia found a negative impact of burnout on performance. The importance of the burnout concept is suggested by its relationships with organizational outcomes, such as absenteeism, turnover, job dissatisfaction, and a decrease in the quality of job performance.(Maslach \& Jackson, 1981).

A negative significant relationship was also established between emotional exhaustion and job performance in a 3 year long study of human services personnel by Wright and Bonett (1997). Based on this context we would hypothesize, that emotional exhaustion is inversely related to job performance in the Kingdom of Saudi Arabia. (Hypothesis 5)

\subsection{Emotional Exhaustion and Job Performance}

The most-used research definition of job satisfaction is by Locke (1976), who defined it as a pleasurable or positive emotional state resulting from the appraisal of one's job or job experiences. Locke's definition gives prominence to both affect or sensation and perception or thinking. When a supervisor provides mentoring, the relationship affects the protégés skill development and intentions to remain with the employer. On the other hand non-supervisory mentor may increase mentee's confidence by providing access to outside organization (Scanduraa and Williams, 2004). The immediate supervisor support is vey important in organizational change. Although the support of supervisor is not very crucial in satisfaction but it has positive impact on satisfaction (Griffin, Patterson and West, 2001). Feelings of success and failure are important determinants of job satisfaction (Locke and Latham. 1990) According to the study accompanied by Friedlander and Margulies (1969), it was revealed that management \& responsive staff relationships contribute to the level of job satisfaction. However, this result contradicts with view of Herzberg (1966) who supported the view that supervision is irrelevant to the level of job satisfaction. And also, even with the widespread recognition of the importance of facilitating the relationship between job satisfaction and emotional exhaustion in facilitating organizational commitment, there are varying perspectives on the means of doing this. One of the strategy is to use wage increases to link job satisfaction and emotional exhaustion to organizational commitment. Built on this background we would hypothesize, that emotional exhaustion is inversely associated with job satisfaction in the Kingdom of Saudi Arabia. (Hypothesis 6)

\section{Objective of the Study}

In an effort to segregate and sort prospective sources of emotional exhaustion, the existing literature is reviewed. The literature analysis also provides a framework that will assist in proving a relationship between emotional exhaustion and job performance, as well as, emotional exhaustion and job satisfaction in the Kingdom of Saudi Arabia.On the basis of the review of literature, the main objective of the study is to assess the relationship between emotional exhaustion \& job performance and also between emotional exhaustion \& job satisfaction in the Kingdom of Saudi Arabia. To achieve the main objective, the following sub objectives were set:

1. To study the level of emotional exhaustion in employees working in the Kingdom of Saudi Arabia.

2. To study the relationship between emotional exhaustion and job performance in the Kingdom of Saudi Arabia. 
3. To study the relationship between emotional exhaustion and job satisfaction in the Kingdom of Saudi Arabia.

\section{Research Methodology}

\subsection{Methodology}

The study is grounded on primary data collected from employees currently working in the Kingdom Saudi Arabia. The researchers furthermore used secondary data for the resolution of this study. A descriptive research design with a survey method is used in this study. The research was proposed on a sample size of 350 respondents. 400 questionnaires were randomly administered to employees. Approximately 320 usable questionnaires were received representing a response rate of $87.5 \%$.

After gathering all the essential data, it was analyzed and tabulated descriptively. And, this tabulated information was used to measure perceived satisfaction and dissatisfaction level of the employees regarding emotional exhaustion and subsequently its relation with job performance and job satisfaction. To measure the satisfaction level a 5 point scale had been used which was denoted by 1=Strongly Disagree, 2=Somewhat Disagree, 3=Neutral, 4=Somewhat Agree, and $5=$ Strongly Agree.

Secondary data collection was done through relevant books, peer journals, and current electronic publications (valid websites). Enough information was attainable from these sources thus allowing for appropriate analysis, compilation, interpretation, and structuring of the entire report.

\subsection{Instrument}

A comprehensive questionnaire, on the subject of the study, was developed for data collection, from the employees working in companies in the Kingdom of Saudi Arabia. The questionnaire was originally developed into English and translated into Arabic for a high response rate.

\subsection{Statistical tool}

The answer filled questionnaire from the respondents was analyzed using SPSS software. Statistical tools used were percentages, mean score and correlation coefficient.

\section{Hypothesis}

Therefore, on the basis of literature review, we suggest the following hypotheses $(H)$ :

$\mathrm{H} 1$ The employees working in the Kingdom of Saudi Arabia do not have compromised physical and mental health.

H2 The employees working in the Kingdom of Saudi Arabia do not have work-overload issues.

H3 The employees working in the Kingdom of Saudi Arabia do not have strained relationship with their colleagues and supervisors.

H4 The employees working in the Kingdom of Saudi Arabia do not have a feeling of negativity at work. H5 Emotional exhaustion is inversely related to Job Performance in the Kingdom of Saudi Arabia. H6 Emotional exhaustion is inversely related to Job Satisfaction in the Kingdom of Saudi Arabia.

\section{Conceptual Framework of the Study}

The researchers completed the study by undertaking the following framework of the study. The study investigates and presents the association between emotional exhaustion and job performance, as well as, emotional exhaustion and job satisfaction, in the Kingdom of Saudi Arabia. The study indicates that emotional exhaustion plays a very important role in enhancing the job performance of an employee and also in enhancing job satisfaction amongst employees working in the Kingdom of Saudi Arabia. 


\section{Results}

\subsection{Demographic results}

$82 \%$ respondents are males and 18\% respondents are female. $75 \%$ are married and $25 \%$ are unmarried.59\% of the respondents have a salary less than 5000 SR and $41 \%$ of the respondents have a salary more than 5000 SR.

\subsection{Relationship results}

The researcher anticipated six hypothesis to be tried in the study to arrive at the significant conclusion. The proposed hypothesis were expected to offer a clear depiction of relationship between emotional exhaustion \& job performance and emotional exhaustion \& job satisfaction in the Kingdom of Saudi Arabia. The results were also likely to show the implications of emotional exhaustion on job performance and job satisfaction of an employee, working in the Kingdom of Saudi Arabia.

\subsubsection{Overall level of Emotional Exhaustion in the Kingdom of Saudi Arabia}

Table 1. Factors of Emotional Exhaustion

\begin{tabular}{|l|c|}
\hline Factors Influencing Emotional Exhaustion & Mean \\
\hline Compromised Physical Health & 51 \\
Excessive Work-load & 51 \\
Supervisor Support and Relationship with Colleagues & 50 \\
Negativity & 51 \\
Average & 51 \\
\hline
\end{tabular}

In terms of factors which influence emotional exhaustion and were under consideration in this research i.e. compromised physical health, work-overload and negativity, the study found that the respondents were more than satisfied or happy about their physical health, work load and were positive about the day to day approach towards their work. And in terms of their relationship with their supervisors and colleagues, the response of the employee's was "Neutral". Overall level of employee response to the four factors of emotional exhaustion under consideration in this study, has an average mean of $51 \%$, so the overall level of employee response is "Somewhat disagree" i.e. the employees in the Kingdom of Saudi Arabia "Somewhat disagree" that the employees have compromised physical and mental health, work-overload issues, negativity related to their work and strained relationship with colleagues and their supervisor's (Table 1).

H1 The employees working in the Kingdom of Saudi Arabia do not have compromised physical and mental health.

In terms of level of physical and mental health of the employees employed in the Kingdom of Saudi Arabia the study establish that 32 respondent's professed it to be as "Neutral". About 89 respondents "Somewhat Disagreed" with the statement that their physical and mental health has compromised due to working conditions in the Kingdom of Saudi Arabia, while 154 respondents "Strongly Disagreed" that their physical and mental health has compromised in the Kingdom of Saudi Arabia. A few, respondents rated that their physical and mental health had been affected "somewhat agree" 21 and "strongly agree" 24 (Table 2).

Table 2. Frequency and Percentage (factors of emotional exhaustion)

\begin{tabular}{l|c|c|c|c|c|c|c|c|}
\hline Satisfaction Level & \multicolumn{2}{|c|}{ Negativity } & \multicolumn{2}{c|}{$\begin{array}{c}\text { Excessive Work- } \\
\text { Load }\end{array}$} & $\begin{array}{c}\text { Strained Relationship with Colleagues and } \\
\text { Supervisor }\end{array}$ & $\begin{array}{c}\text { Compromised Physical and } \\
\text { Mental Health }\end{array}$ \\
\hline & $\mathrm{N}$ & $\%$ & $\mathrm{~N}$ & $\%$ & $\mathrm{~N}$ & $\%$ & $\mathrm{~N}$ & $\%$ \\
Strongly disagree & 150 & 46.88 & 150 & 46.88 & 152 & 47.50 & 154 & 48.13 \\
Somewhat Disagree & 85 & 26.56 & 85 & 26.56 & 88 & 27.50 & 89 & 27.81 \\
Neutral & 36 & 11.25 & 40 & 12.50 & 39 & 12.19 & 32 & 10.00 \\
Somewhat agree & 29 & 9.06 & 25 & 7.81 & 23 & 7.19 & 21 & 6.56 \\
Strongly Agree & 20 & 6.25 & 20 & 6.25 & 18 & 5.63 & 24 & 7.50 \\
Total & 320 & 100 & 320 & 100 & 320 & 100 & 320 & 100 \\
\hline
\end{tabular}


And Also, the mean score is 2.54 , which denotes that the employees "somewhat disagree" to the statement that their physical and mental health has been affected by being employed in the Kingdom of Saudi Arabia. Observing the mean score of 2.54, we can say that the employees working in the Kingdom of Saudi Arabia have good physical and mental health. (Table 3)

Table 3. About Compromised Physical and Mental Health

\begin{tabular}{|l|c|c|c|c|}
\hline Satisfaction Level & Value of $(\mathbf{X})$ & Frequency $(\mathrm{f}) \%$ & $\mathrm{~d}=\mathbf{X}-\mathbf{A}$ & $\mathrm{fd}$ \\
\hline Strongly Disagree & 1 & 48 & -2 & -48 \\
Somewhat Disagree & 2 & 28 & -1 & -28 \\
Neutral & $3(\mathrm{~A})$ & 10 & 0 & -10 \\
Somewhat Agree & 4 & 7 & 1 & 14 \\
Strongly Agree & 5 & 8 & 2 & 16 \\
& & $\sum \mathrm{fd}=100$ & & $\sum \mathrm{fd}=-46$ \\
\hline
\end{tabular}

$X=A+(\Sigma f d / \Sigma f)$

$=3+(-46 / 100)=2.54$

$=2.54 \times 20$

$=51 \%$

H2 The personnel working in the Kingdom of Saudi Arabia do not have work-over load issues.

In terms of work-overload, the study establish that 40 respondent's professed it to be as "Neutral". About 85 respondents "Somewhat Disagreed" with the statement that their employers give them work-overload in the Kingdom of Saudi Arabia, while 150 respondents "Strongly Disagreed" to with excessive work-load issues. A few respondents though, 25 rated that they "somewhat agree" with the fact that there is an issue of excessive work-load, while 20 respondents "strongly agreed" to the fact they had to face issue of excessive work-load, in their jobs. (Table 2)

And Also, the mean score is 2.55 , which denotes that the employees "somewhat disagree" they had issue of workoverload, while working in the Kingdom of Saudi Arabia. Observing the mean score of 2.55, we can say that the personnel employed in the Kingdom of Saudi Arabia have good working conditions and they mostly do not have to face problems related to work-over load.

Table 4. About Work-Overload

\begin{tabular}{|c|c|c|c|c|}
\hline Satisfaction Level & Value of $(X)$ & Frequency (f)\% & $d=X-A$ & $\mathrm{fd}$ \\
\hline Strongly Disagree & 1 & 47 & -2 & -47 \\
\hline Somewhat Disagree & 2 & 27 & -1 & -27 \\
\hline Neutral & $3(A)$ & 13 & 0 & 0 \\
\hline Somewhat Agree & 4 & 8 & 1 & 16 \\
\hline Strongly Agree & 5 & 6 & 2 & 12 \\
\hline & & $\Sigma \mathrm{fd}=100$ & & $\Sigma \mathrm{fd}=-45$ \\
\hline
\end{tabular}

H3 The employees working in the Kingdom of Saudi Arabia do not have strained relationships with their colleagues and supervisors.

In terms of strained relationships with their colleagues and supervisors, the study found that 39 respondent's perceived it to be as "Neutral". About 88 respondents "Somewhat Disagreed" with the statement that they had strained relationships with their colleagues and supervisors, while 152 respondents "Strongly Disagreed" to it. A few respondents though, 23 rated that they "somewhat agree" with the fact that they have strained relations with their colleagues and supervisors, while 16 respondents "strongly agreed" to the fact they actually have a strained relationship with their colleagues and supervisors. (Table 2)

And Also, the mean score is 2.50 , which denotes that the employees "somewhat disagree" they have strained relationships with their colleagues and supervisors in the Kingdom of Saudi Arabia. Observing the mean score of 2.50, we can say that the personnel employed in the Kingdom of Saudi Arabia have good goo relationships with their 
colleagues as well as, with their supervisors.

Table 5. About Strained Relationship with colleagues

\begin{tabular}{|c|c|c|c|c|}
\hline Satisfaction Level & Value of $(X)$ & Frequency (f) $\%$ & $d=X-A$ & fd \\
\hline Strongly Disagree & 1 & 48 & -2 & -48 \\
\hline Somewhat Disagree & 2 & 28 & -1 & -28 \\
\hline Neutral & $3(A)$ & 12 & 0 & 0 \\
\hline Somewhat Agree & 4 & 7 & 1 & 14 \\
\hline Strongly Agree & 5 & 6 & 2 & 12 \\
\hline & & $\Sigma \mathrm{fd}=100$ & & $\Sigma f d=-50$ \\
\hline
\end{tabular}

$\mathrm{H} 4$ The employees working in the Kingdom of Saudi Arabia do not have a feeling of negativity at work.

In terms of having a feeling of negativity at work, the study found that 39 respondent's professed it to be as "Neutral". About 85 respondents "Somewhat Disagreed" with the statement that they had a feeling a negativity at work, while 150 respondents "Strongly Disagreed" to it. A few respondents though, 29 rated that they "somewhat agree" with the fact that they have a feeling of negativity at work, while 20 respondents "strongly agreed" to the fact they actually have a feeling of negativity at work. (Table 2 )

And Also, the mean score is 2.57 , which denotes that the employees "somewhat disagree" about having a feeling of negativity at work, while employed in the Kingdom of Saudi Arabia. Looking at the mean score of 2.57, we can say that the personnel working in the Kingdom of Saudi Arabia have are very positive approach towards their work.

Table 6. About Feeling of Negativity at Work

\begin{tabular}{|l|c|c|c|c|}
\hline Satisfaction Level & Value of $(\mathbf{X})$ & Frequency $(\mathrm{f}) \%$ & $\mathrm{~d}=\mathbf{X}-\mathbf{A}$ & $\mathrm{fd}$ \\
\hline Strongly Disagree & 1 & 47 & -2 & -47 \\
Somewhat Disagree & 2 & 27 & -1 & -27 \\
Neutral & $3(\mathrm{~A})$ & 11 & 0 & 0 \\
Somewhat Agree & 4 & 9 & 1 & 18 \\
Strongly Agree & 5 & 6 & 2 & 12 \\
& & $\Sigma \mathrm{fd}=100$ & & $\Sigma \mathrm{fd}=-43$ \\
$\mathrm{X}=\mathrm{A}+(\Sigma \mathrm{fd} / / \mathrm{ff})$ & \\
$=3+(-43 / 100)=2.57$ & \\
$=2.57 \times 20$ &
\end{tabular}

H5 Emotional exhaustion is inversely related to better job performance.

Table 7 shows that $83.13 \%$ of employees are happy with their job performance and they either "Strongly Disagree" or "Somewhat Disagree" with the statement that their job performance at work is not satisfactory (Strongly Disagree 48.75\%, Somewhat disagree 23.13\%, Neutral 11.25\%).

Table 7. About Job Satisfaction and Job Performance

\begin{tabular}{|l|c|c|c|c|}
\hline \multirow{2}{*}{ Satisfaction Level } & \multicolumn{2}{|c|}{ No Job Satisfaction } & \multicolumn{2}{c|}{ No Job Performance } \\
\cline { 2 - 5 } & $\mathbf{N}$ & $\%$ & $\mathbf{N}$ & $\%$ \\
\hline Strongly disagree & 150 & 46.88 & 156 & 48.75 \\
Somewhat Disagree & 85 & 26.56 & 74 & 23.13 \\
Neutral & 40 & 12.50 & 36 & 11.25 \\
Somewhat agree & 25 & 7.81 & 29 & 9.06 \\
Strongly Agree & 20 & 6.25 & 25 & 7.81 \\
Total & 320 & 100 & 320 & 100 \\
\hline
\end{tabular}


And also from Table 8 the researchers conclude that there is a association between better job performance and emotional exhaustion. The more job performance the lesser the emotional exhaustion. The correlation coefficient's of $0.99,0.99,0.98,0.98$ for negativity at work, work-overload, strained relationship with colleagues \& supervisor and compromised physical \& mental health respectively, depicts that there is a strong but inverse relationship between job performance and emotional exhaustion. And also, the employees working in the Kingdom of Saudi Arabia are happy with their job performance at work.

Table 8. Correlation between Job Performance and Emotional Exhaustion

\begin{tabular}{|c|c|c|c|c|c|}
\hline Satisfaction Level & \begin{tabular}{|c|} 
No Job \\
Performance
\end{tabular} & Negativity at Work & Work Overload & $\begin{array}{c}\text { Strained } \\
\text { Relationships }\end{array}$ & $\begin{array}{l}\text { Compromised Physical } \\
\text { and Mental Health }\end{array}$ \\
\hline \multirow[t]{3}{*}{$\begin{array}{l}\text { Strongly disagree } \\
\text { Somewhat Disagree } \\
\text { Neutral } \\
\text { Somewhat agree } \\
\text { Strongly Agree } \\
\end{array}$} & $\begin{array}{c}156 \\
74 \\
36 \\
29 \\
25\end{array}$ & $\begin{array}{c}150 \\
85 \\
36 \\
29 \\
20\end{array}$ & $\begin{array}{c}152 \\
91 \\
34 \\
25 \\
18\end{array}$ & $\begin{array}{c}150 \\
85 \\
40 \\
25 \\
20\end{array}$ & $\begin{array}{c}152 \\
88 \\
39 \\
23 \\
18\end{array}$ \\
\hline & $\begin{array}{l}\text { Correlation } \\
\text { Coefficient }\end{array}$ & 0.992462 & 0.985758 & 0.991113 & 0.988016 \\
\hline & $\begin{array}{l}\text { Variance } \\
\text { Explained }\end{array}$ & 98 & 97 & 98 & 98 \\
\hline
\end{tabular}

H6 Emotional exhaustion is inversely related to better job satisfaction.

Table 7 shows that $85.94 \%$ of personnel are satisfied with their job's and they either "Strongly Disagree" or "Somewhat Disagree" with the statement that they are not satisfied with their respective job's (Strongly Disagree 46.88\%, Somewhat disagree $26.56 \%$, Neutral $12.50 \%$ ).

And also from Table 9 the researchers conclude that there is a association between better job satisfaction and emotional exhaustion. The more the job satisfaction the lesser the emotional exhaustion and vice versa. The correlation coefficients of $0.99,1,0.99,0.99$ for negativity at work, work-overload, strained relationship with colleagues \& supervisor and compromised physical \& mental health respectively, depicts that there is a strong but inverse relationship between job satisfaction and emotional exhaustion. And also, the employees working in the Kingdom of Saudi Arabia are satisfied with their job's.

Table 9. Correlation between Job Satisfaction and Emotional Exhaustion

\begin{tabular}{|c|c|c|c|c|c|}
\hline Satisfactin Level & $\begin{array}{c}\text { No Job } \\
\text { Satisfaction }\end{array}$ & $\begin{array}{c}\text { Negativity at } \\
\text { Work }\end{array}$ & Work Overload & $\begin{array}{c}\text { Strained } \\
\text { Relationships }\end{array}$ & $\begin{array}{l}\text { Compromised Physical } \\
\text { and Mental Health }\end{array}$ \\
\hline \multirow[t]{3}{*}{$\begin{array}{l}\text { Strongly disagree } \\
\text { Somewhat Disagree } \\
\text { Neutral } \\
\text { Somewhat agree } \\
\text { Strongly Agree } \\
\end{array}$} & $\begin{array}{c}150 \\
85 \\
40 \\
25 \\
20\end{array}$ & $\begin{array}{c}150 \\
85 \\
36 \\
29 \\
20\end{array}$ & $\begin{array}{c}150 \\
85 \\
40 \\
25 \\
20\end{array}$ & $\begin{array}{c}152 \\
88 \\
39 \\
23 \\
18\end{array}$ & $\begin{array}{c}154 \\
89 \\
32 \\
21 \\
24\end{array}$ \\
\hline & $\begin{array}{l}\text { Correlation } \\
\text { Coefficient }\end{array}$ & 0.998654 & 1 & 0.999734 & 0.996293 \\
\hline & $\begin{array}{l}\text { Variance } \\
\text { Explained }\end{array}$ & 100 & 100 & 100 & 99 \\
\hline
\end{tabular}

\section{Findings}

The researchers suggested six hypotheses to be tried in the study to reach at the significant conclusion. The proposed hypotheses were anticipated to provide unblemished depiction on the impact of emotional exhaustion on personnel working in the Kingdom of Saudi Arabia and their influence on job performance and job satisfaction of an employee. The results were also expected to show the association between emotional exhaustion \& job performance and emotional exhaustion \& job satisfaction in the Kingdom of Saudi Arabia's. From the outcomes and analysis the researchers presents the following highlights of the finding. 


\begin{tabular}{|c|c|c|c|}
\hline & & \multicolumn{2}{|l|}{ Summary of hypothesis and brief findings. } \\
\hline$(1)$ & $(2)$ & (3) & (4) \\
\hline $\mathrm{H} 1$ & Yes & The employees do not have compromised physical and mental health. & Accepted \\
\hline $\mathrm{H} 2$ & Yes & The employees do not have issues of work-overload. & Accepted \\
\hline H3 & Yes & The employees do not have strained relationships at work. & Accepted \\
\hline $\mathrm{H} 4$ & Yes & The employees do not have a feeling of negativity at work. & Accepted \\
\hline H5 & Yes & Job performance is inversely related to emotional exhaustion & Accepted \\
\hline $\mathrm{H} 6$ & Yes & Job satisfaction is inversely related to emotional exhaustion & Accepted \\
\hline
\end{tabular}

NOTES Column headings are as follows: (1) hypothesis, (2) Correlation (3) results, (4) hypothesis rejected/accepted.

\section{Discussion}

In the present study the researchers offered six hypotheses to test, through which three objectives would be attained. In this segment the results of the study and objectives are debated.

The results of the study show that employees are happy with their job performance and job satisfaction. Although $59 \%$ of the respondents said that their salary is below 5000 SR but at the same time more percentage of employee's i.e. $73 \%$ \& $71 \%$ of employees were satisfied with their jobs and their job performance at work, respectively. The reason for this is that working in Saudi Arabia comes with some considerable financial benefits. Not only are salaries slightly higher than for the same kind of work in other countries, but the net income receives a significant boost through the absence of personal income tax.

The first objective of the research was to study the level of emotional exhaustion in employees working in the Kingdom of Saudi Arabia. For the purpose of this objective, the researchers shortlisted four factors of emotional exhaustion from the literature review and proposed four hypothesis, with the sub objectives of finding the impact of emotional exhaustion, for each one of them, on personnel working in the Kingdom of Saudi Arabia. The following were the four factors of emotional exhaustion, namely, compromised physical \& mental health, work-overload, strained relationship with colleagues \& supervisors and negativity at work. The result showed that approximately $86 \%$ of the respondents are satisfied with their physical and mental health while working in the Kingdom of Saudi Arabia i.e.48.13\% "Strongly Disagree", 27.81\%"Somewhat Disagree",10\% "Neutral" to the statement that their physical and mental health has been compromised in the Kingdom of Saudi Arabia. However 14\% said that they strongly or somewhat agreed with this. The researchers found that the mean score is 2.54 , which depicts that the employees "somewhat disagree" with the emotional exhaustion factor of compromised physical and mental health in the Kingdom of Saudi Arabia.

The result also showed that approximately $85.94 \%$ of the respondents "disagree" about work-overload issues in the Kingdom of Saudi Arabia i.e.46.88\% "Strongly Disagree", 26.56\% "Somewhat Disagree", 12.50\% "Neutral". However $14.06 \%$ said that they strongly or somewhat agree with work-overload issues prevailing in the Kingdom of Saudi Arabia. The researchers found that the mean score is 2.55 , which depicts that the employees "somewhat disagree" with workoverload issues in the Kingdom of Saudi Arabia.

The result further showed that approximately $87.19 \%$ of the respondents "disagree" about having strained relationships with their colleagues and supervisor's, in the Kingdom of Saudi Arabia i.e.47.50\% "Strongly Disagree", 27.50\% "Somewhat Disagree", $12.19 \%$ "Neutral". However $12.81 \%$ said that they strongly or somewhat agree with strained relationship with their colleagues and supervisor's in the Kingdom of Saudi Arabia. The researchers found that the mean score is 2.50 , which depicts that the employees "somewhat disagree" when the researchers proposed that the employees working in the Kingdom of Saudi Arabia, had strained relationship with their colleagues and supervisor's.

The result showed that approximately $84.69 \%$ of the respondents "disagree" about having a negative feeling at work, in the Kingdom of Saudi Arabia i.e.46.88\% "Strongly Disagree", 26.56\% "Somewhat Disagree", 11.25\% "Neutral". However $15.31 \%$ said that they strongly or somewhat agree with having a negative feeling about being employed in the Kingdom of Saudi Arabia. The researchers found that the mean score is 2.57, which depicts that the employees "somewhat disagree" with the emotional exhaustion factor of having a feeling of negativity at work, in the Kingdom of Saudi Arabia.

Overall level of employee response to the four factors of emotional exhaustion under consideration in this study, has an average mean of $51 \%$, so the overall level of employee response is "Somewhat disagree" i.e. the employees in the Kingdom of Saudi Arabia "Somewhat disagree" that the employees have compromise physical and mental health, work-load issues, negativity related to their work and strained relationship between colleagues and their supervisor's.

The second objective of the study was to study the association between emotional exhaustion and job performance, in the Kingdom of Saudi Arabia. And the researchers found out that there is an association between 
emotional exhaustion and job performance. For the purpose of this objective, the researchers proposed a hypothesis.

The researchers found that job performance was inversely related to compromised physical and mental health, as $85.94 \%$ of the respondents said that they "disagree" about having a compromised physical \& mental health and also almost the same percentage of respondents i.e 83.14\% "disagreed" about having no job performance while working for organizations in the Kingdom of Saudi Arabia. The correlation coefficient of 0.98 between job performance and compromised physical \& mental health showed that there is durable but inverse relationship between job performance and compromised physical \& mental health. The researchers further found a inverse and strong relationship between job performance and work-load, as $85.94 \%$ of employees "disagree" that they have work-over load issue, while working in the Kingdom of Saudi Arabia and also almost the same percentage of respondents i.e 83.14\% "disagreed" about having no job performance while working for organizations in the Kingdom of Saudi Arabia. The correlation coefficient of 0.99 between job performance and work-load showed that there is strong but inverse association between job performance and work-overload. The researchers further found that job performance is inversely related to strained relationships with colleagues \& supervisor's, as $87.19 \%$ of employees "disagree" with this and also almost the same percentage of respondents i.e 83.14\% "disagreed" about having no job performance while working for organizations in the Kingdom of Saudi Arabia. The correlation coefficient of 0.98 between job performance and strained relationships with colleagues \& supervisor's depicts a strong but inverse relationship between the two. Further the researchers found an inverse but strong relationship between job performance and negativity at work, as $84.69 \%$ of employees "disagree" having negativity at work and also almost the same percentage of respondent's i.e 83.14\% "disagreed" about having no job performance while working for organizations in the Kingdom of Saudi Arabia. The correlation coefficient of 0.99 between job performance and negativity at work showed that there is strong and inverse association between job performance and negativity at work. Thus, job performance and factors of emotional exhaustion are inversely related to each other.

The third objective of the study was to study the relationship between emotional exhaustion and job satisfaction, in the Kingdom of Saudi Arabia. And the researchers found out that there is a association between emotional exhaustion and job satisfaction. For the purpose of this objective, the researchers proposed a hypothesis.

The researchers found that job satisfaction was inversely linked to compromised physical and mental health, as $85.94 \%$ of the respondents said that they "disagree" about having a compromised physical \& mental health and also almost the same percentage of respondents i.e $85.94 \%$ "disagreed" about having no job satisfaction while working for organizations in the Kingdom of Saudi Arabia. The correlation coefficient of 0.98 between job satisfaction and compromised physical \& mental health showed that there is durable but inverse relationship between job satisfaction and compromised physical \& mental health. The researchers further found a inverse and strong relationship between job satisfaction and work-load, as $85.94 \%$ of employees "disagree" that they have work-over load issue, while working in the Kingdom of Saudi Arabia and also almost the same percentage of respondents i.e 85.94\% "disagreed" about having no job satisfaction while working for organizations in the Kingdom of Saudi Arabia. The correlation coefficient of 1 between job satisfaction and work-load showed that there is strong but inverse relationship between job satisfaction and workoverload. The researchers further found that job satisfaction is inversely linked to strained relationships with colleagues \& supervisor's, as $87.19 \%$ of employees "disagree" with this and also almost the same percentage of respondents i.e 85.94\% "disagreed" about having no job satisfaction while working for organizations in the Kingdom of Saudi Arabia. The correlation coefficient of 0.99 between job satisfaction and strained relationships with colleagues \& supervisor's depicts a strong but inverse relationship between the two. Further the researchers found an inverse but strong relationship between job satisfaction and negativity at work, as $84.69 \%$ of employees "disagree" having negativity at and also almost the same percentage of respondents i.e $85.94 \%$ "disagreed" about having no job satisfaction while working for organizations in the Kingdom of Saudi Arabia. The correlation coefficient of 0.99 between job satisfaction and negativity at work showed that there is sturdy and inverse association between job satisfaction and negativity at work. Thus, job satisfaction and factors of emotional exhaustion are inversely related to each other.

Thus the from the above result, the researchers found out that there is an association between emotional exhaustion, job performance and emotional exhaustion, job satisfaction, for employee, working in the Kingdom of Saudi Arabia.

Grounded on the above discussion, literature review, previous research findings and the findings from the empirical analysis of the current research, the study also presents an association between emotional exhaustion, job performance and emotional exhaustion, job satisfaction; this study presents a model which proposes the impact and subsequent consequences of emotional exhaustion on personnel working in different organizations across different sectors in the Kingdom of Saudi Arabia The present model thus proposes the impact of compensation on job performance, work-family conflict and vice versa, through three different paths, as follows. 


\section{Concluding Remarks and Practicle Implications}

From the abovementioned study, and investigation the researchers unveiled the level of emotional exhaustion in the personnel employed in the Kingdom of Saudi Arabia and also the relationship between emotional exhaustion, job performance and emotional exhaustion, job satisfaction, with reference to the Kingdom of Saudi Arabia.

And also this study is expected to contribute to the literature related to emotional exhaustion, job performance and job satisfaction concerning employees, working in different organization across the Kingdom of Saudi Arabia. Organization operating in the Kingdom of Saudi Arabia should also be aware about the about the effects of emotional exhaustion on the job performance and compensation of an employee and thus should pay close attention to it.

The researchers assertively conclude that this research work has practical and policy insinuations for the establishments operating in the Kingdom of Saudi Arabia. The finding present that although the employees working in the Kingdom do not show alarming level of signs related to emotional exhaustion but organizations can improve the performance of personnel by additionally emphasizing on mitigating the emotional exhaustion of employees. It is worth mentioning here that the study found that the impact of lower level of emotional exhaustion has a positive impact on the job performance and job satisfaction of the employees working in different sectors of Saudi Arabia. And thus, emotional exhaustion has a strong and inverse relationship with job performance and job satisfaction of employees, working in the Kingdom of Saudi Arabia.

\section{Limitations and Future Research Directions}

The study and the subsequent model is grounded on data composed from employees working in the Kingdom of Saudi Arabia only, which could have been collected from other regions of the middle east countries. Further the survey is subjected to the bias and prejudices of the respondents. Hence 100\% accuracy can't be assured. And also, future researchers can take up studies on human resource management by including the above mentioned limitations.

\section{Acknowledgement}

We would like to extend our thanks to overall administration and the policy of King Abdulaziz University in general, in encouraging and promoting the research activities. However we would like to extend our gratefulness to the Deanship of Scientific Research for their continuous support and guidance in conducting this study and making it a reality.

\section{References}

Arnolds, C.A., \& Boshoff, C. (2001). The challenge of motivating top management: A need satisfaction perspective [Electronic version]. Journal of Industrial Psychology, 27(1), 39-42.

Bartely,S.H., \& Chute,E. Fatigue and impairment in man. New York: McGraw-Hill,.1947.

Campion, M., Fink, A. \& Ruggeberg, B. et al. (2011). Doing competencies well: best practices incompetency modeling. Personnel Psychology. Vol. 64: 225-62.

Capko, J. (2003). 5 Steps to a Performance Evaluation System. Retrieved from http://www.aafp.org/fpm/2003/0300/p43.html

Caplan, R. D., Cobb, S., French, J. R. P.,Harrison, R. V. and Pinneau, S. R. (1975). Job Demands and Worker Health (Report No. 75160). Washington, DC: US Department of Health, Education and Welfare.

Cherniss, C. Staff burnout: Job stress in the human services. Beverly Hills: Sage publications 1980

Cordes, C. L. and Dougherty, T. W. (1993). 'A review and an integration of research on job burnout'. Academy of Management Review, $18,4,621-56$.

Emotional exhaustion, the freedictionary. Accessed on 14 November 2013: http://encyclopedia.thefreedictionary.com/emotional+ exhaustion

F. Friedlander, and N. Margulies (1969) Multiple Impacts of Organization Climate and Individual Values System upon Job Satisfaction,Personnel Psychology. 22, pp. 177-183.

F. Herzberg (1966) Work and the Nature of Man. Staple Press. London.

Freudenberget, H.J. Staff burn-out. Journal of Social Issues, 1974,30, 159-165

Greenberg, J., \& Baron, R. A. (1993). Behavior in organizations (4th ed.). Needham Heights, MA: Allyn and Bacon.

Griffin MA, Patterson MG, West MA (2001). Job satisfaction and team work: the role of supervisor support. J. Organ. Behav., 22: 537550.

Griffith, J.W., Kerr, W.A.,Mayo,T.B., \& Topal, J.R. Changes in subjective fatigue and readiness for work during the eighth hour shift. Journal of Applied Psychology, 1950, 34, 163-166

Hochschild, A. (1979). 'Emotion work, feeling rules, and social structure'. American Journal of Sociology, 85, 551-75. 
Jackson, S. E., Schwab, R. L. and Schuler, R. S. (1986). 'Toward an understanding of the burnout phenomenon'. Journal of Applied Psychology, 71, 630-40.

Judge, T. A., Locke, E. A., Durham, C. C., \&Kluger, A. N. 1998. Dispositional effects on job and life satisfaction: The role of core evaluations. Journal of Applied Psychology, 83, 17-34.

Judge, T. A., \& Bono, J. E. 2001. Relationship of core self-evaluations traits-self-esteem, generalized self-efficacy, locus of control, and emotional stability—with job satisfaction and job performance: A meta-analysis. Journal of Applied Psychology, 86, 80-92

Lee ,R. T. and Ashforth, B. E. (1996). 'A meta-analytic examination of the correlates of the three dimensions of job burnout'. Journal of Applied Psychology, 2, 123-33.

Lo, G. S., Cravens, D. W., Grant, K., \& Moncrief, W. C. (2001). Antecedents and consequences of salesperson burnout. European Journal of Marketing, 35(5/6), 587-611.

Locke,E.A.1976.Thenatureandcausesofjobsatisfaction.InM.D.Dunnette(Ed.),Handbookofindustrialandorganizationalpsychology(pp.12971349).Chicago:RandMcNally

LockeE.A.andLatham.G.P.1990.ATheoryofGoalSettingandTaskPerformance, Prentice Hall. EnglewoodCliff",NewJersey

Maslach, C. Burn-Out. Human Behavior.1976, 5(9). 16-22

Maslach, C. Understanding burnout: Definitional issues in analyzing a complex phenomenon. In W. S. Paine (Ed.). Job Stress and burnout: Research, theory, and intervention perspectives. Beverly Hills ; Sage focus editions, 1982, 29-40

Maslach, C., \& Jackson, S.E. The measurement of experienced burnout. Journal of occupational behavior, 1981, 2, 99-113

Maslach, C. and Pines, A. (1977). 'The burn-out syndrome in the day care setting'. Child Care Quarterly, 6, 100-13.

Moore, J. E. (2000). 'Why is this happening? A causal attribution approach to work exhaustion consequences'. Academy of Management Review, 25, 2, 335-49.

Mooris, J. A. and Feldman, D. C. (1997). 'Managing emotions in the workplace'. Journal of Managerial Issues, IX, 3, Fall, $257-74$.

Mattingly, M.A. Sources of stress and burn-out in professional child care work. Child care quarterly, 1977,6,127-137.

Scanduraa TA, Williams EA (2004). Mentoring and transformational leadership: The role of supervisory career mentoring. J. Vocat. Behav., 65: 448-468.

Ulrich,D., and D.Lake.(1990). Organizational capability. New York:Wiley.

Wharton, A. S. (1993). 'The affective consequences of service work'. Work and Occupations, 205-32.

Wright, T. A., \& Bonett, D. G. (1997). The contribution of burnout to work performance, Journal of Vocational Behavior, 18, 491-499.

Wright TA, Cropanzano R (June 1998). "Emotional exhaustion as a predictor of job performance and voluntary turnover". Journal of Applied Psychology, 83 (3), 486-493

Zohar D. (1997). "Predicting burnout with a hassle-based measure of role demands". Journal of Organizational Behavior 18 (2): $101-115$ 